\title{
On an extraordinarily high strength of a two-phase VT8-based titanium alloy heavy alloyed with zirconium
}

\author{
R.A. Gaisin ${ }^{\dagger}$, V.M. Imayev, E.R. Gaisina, R.A. Shaimardanov, R.M. Imayev \\ †ramilgaisin@gmail.com
}

Institute for Metals Superplasticity Problems of RAS, Ul. Khalturina 39, 450001, Ufa, Russia

\begin{abstract}
A novel two-phase titanium alloy based on VT8 (Ti-6.5Al-3.3Mo-0.3Si) having the composition VT8-20Zr-0.1B (wt. \%) has been considered in the present paper. It has been established that modifying with boron leads to refinement of prior $\beta$ grains and $\alpha / \beta$ colonies by a factor of about ten and alloying with zirconium results in some additional colony refinement. Alloying with 20 wt. \% of zirconium leads to decreasing the $\alpha+\beta \rightarrow \beta$ transformation temperature by about $100^{\circ} \mathrm{C}$ that along with refinement of the as-cast structure improved the hot workability of the alloy. After multidirectional hot forging in the $\alpha+\beta$ phase field $\left(T=800^{\circ} \mathrm{C}\right)$ and hardening heat treatment the strength of the BT8-20Zr- $0.1 \mathrm{~B}$ alloy at $20-500^{\circ} \mathrm{C}$ was found to be higher by $30-40 \%$ as compared with that of the VT8 alloy after the same treatment while retaining similar ductility of the alloys. This allows one to characterize the VT8-20Zr-0.1B alloy as an ultrastrong titanium alloy. For the VT8-20Zr-0.1B alloy the following tensile properties have been attained: $\sigma_{\mathrm{UTS}}=1560 \mathrm{MPa}$ and $\delta=4 \%$ at room temperature, $\sigma_{\mathrm{UTS}}=1230 \mathrm{MPa}$ and

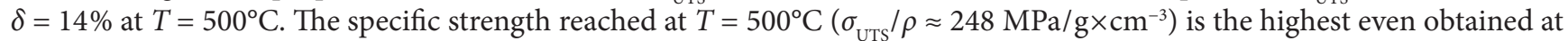
this temperature for currently known titanium alloys. It was revealed that water quenching from the $\beta$ phase field led to the martensitic $\beta \rightarrow \alpha^{\prime \prime}$ transformation with retained $\beta$ phase and subsequent ageing resulted in formation of ultrafine lamellar structure with a nanosized lamellae thickness that promoted achieving significant strengthening.
\end{abstract}

Keywords: titanium alloys, microstructure, hardening heat treatment, mechanical properties.

\section{О необычно высокой прочности двухфазного титанового сплава на основе ВТ8, высоколегированного цирконием}

\author{
Гайсин Р.А. ${ }^{\dagger}$, Имаев В.М., Гайсина Э.Р., Шаймарданов Р.А., Имаев Р.М. \\ †ramilgaisin@gmail.com
}

Институт проблем сверхпластичности металлов РАН, ул. Халтурина 39, 450001, Уфа, Россия

В статье рассматривается новый двухфазный титановый сплав на основе ВТ8 (Ti-6,5Al-3,3Mo-0,3Si) состава BT8-20Zr-0,1B (вес. \%). Установлено, что модифицирование бором обеспечивает измельчение размера исходных $\beta$-зерен и $\alpha / \beta$ колоний в слитке примерно на порядок, а легирование цирконием дополнительно измельчает размер колоний в слитке. Легирование сплава ВТ8 цирконием в количестве 20 вес.\% снижает температуру $\alpha+\beta \rightarrow \beta$ превращения примерно на $100^{\circ} \mathrm{C}$, что вместе с измельчением структуры слитка способствует улучшению деформируемости сплава при повышенных температурах. После всесторонней изотермической ковки при температуре $\alpha+\beta$ фазовой области $\left(T=800^{\circ} \mathrm{C}\right)$ и упрочняющей термической обработки прочность сплава BT8-20Zr-0,1B при 20 - $500^{\circ} \mathrm{C}$ оказалась на 30 - 40\% выше прочности ВТ8 после аналогичной обработки при близких значениях пластичности, что дает основание причислить полученный сплав к сверхпрочным титановым сплавам. Для сплава BT8-20Zr-0,1B были достигнуты следующие свойства при растяжении: $\sigma_{\mathrm{B}}=1560 \mathrm{MПа} \mathrm{и} \delta=4 \%$ при комнатной температуре, $\sigma_{\mathrm{B}}=1230 \mathrm{MПа}$ и $\delta=14 \%$ при $T=500^{\circ} \mathrm{C}$. Достигнутая удельная прочность при $T=500^{\circ} \mathrm{C}\left(\sigma_{\mathrm{B}} / \rho \approx 248 \mathrm{MПа} / \Gamma \times \mathrm{cm}^{-3}\right)$ является рекордной при этой температуре для известных титановых сплавов. Установлено, что закалка сплава в воду от температур $\beta$ фазовой области приводит к мартенситному $\beta \rightarrow \alpha^{\prime \prime}$ превращению с сохранением остаточной $\beta$-фазы, а последующее старение - к формированию тонкодисперсной пластинчатой структуры с нанометрической толщиной пластин, обеспечивающей значительное упрочнение.

Ключевые слова: титановые сплавы, микроструктура, упрочняющая термическая обработка, механические свойства. 


\section{1. Введение}

Титановые сплавы, обладающие высокой удельной прочностью и превосходной коррозионной стойкостью, являются важнейшими конструкционными материалами для авиационной, космической промышленности, медицины и др. Титановые сплавы разделяют на $\alpha$ (псевдо $\alpha), \alpha+\beta$ и $\beta$ (псевдо $\beta$ ) сплавы в соответствии с их фазовым составом [1-3]. Наиболее прочные титановые сплавы - это $\beta$ или $\alpha+\beta$ титановые сплавы, имеющие максимальную рабочую температуру обычно не более $T=300-350^{\circ} \mathrm{C}$. Например, $\beta$ титановые сплавы TIMETAL 125 (Ti-6V-6Mo-6Fe-3Al) и BT19 (Ti-3Al-5,5Mo-3,5V-5,5Cr-1Zr) могут иметь при комнатной температуре соответственно $\sigma_{\text {в }}=1620$ МПа при $\delta=6 \%$ [3] и $\sigma_{\text {в }}=1550-1700$ МПа при $\delta=3-6 \%$ [4], т. е. высокие значения прочности и приемлемые значения пластичности при сравнительно низкой жаропрочности. В более жаропрочных $\alpha+\beta$ и $\alpha$ титановых сплавах достижение столь высоких значений прочности при сохранении высокой жаропрочности и приемлемой пластичности затруднено, поскольку такие сплавы не обладают достаточной способностью к термическому упрочнению, а с помощью деформационного упрочнения, в том числе через создание ультрамелкозернистой структуры, не удается сохранить требуемую жаропрочность.

В настоящей работе исследовали экспериментальный титановый сплав на основе ВТ8 - сплав состава BT8-20Zr-0,1B (вес. \%). Цирконий принадлежит к той же (IVB) подгруппе периодической таблицы, что и титан, и потому имеет неограниченную растворимость в титане. Цирконий известен как нейтральный (близкий к нейтральному) упрочнитель титановых сплавов, который используется в качестве легирующего элемента в количестве, обычно не превышающем 3-4,5 вес. \% [1-3]. Между тем, как было показано недавно [5, 6], высокое содержание циркония обеспечивает эффективное термическое упрочнение, которое, по-видимому, может сохраняться до высоких температур. Экспериментальный сплав был также модифицирован бором, который позволяет существенно измельчить исходную литую структуру благодаря формированию в объеме слитка коротких волокон/частиц моноборида титана, тем самым облегчая деформационную обработку исходного слитка, а также открывая возможность проведения $\beta$-терми- ческой обработки без риска неконтролируемого роста $\beta$-зерен [7-11].

Цель настоящей работы - достижение улучшенных механических свойств в сплаве ВТ8 за счет высокого легирования цирконием и модифицирования бором. Заготовки сплава подвергали всесторонней изотермической ковке и последующей упрочняющей термической обработке, режимы которой подбирались из условия сохранения высокой жаропрочности сплава (возможности применения до $T=500^{\circ} \mathrm{C}-$ максимальной рабочей температуры сплава ВТ8).

\section{2. Материалы и методики эксперимента}

В качестве материалов для исследования были взяты три сплава, составы которых представлены в таблице 1. Все сплавы были выплавлены в лабораторной плавильной установке методом аргонно-дуговой плавки в виде 100-граммовых слитков. Как исходные материалы при выплавке были использованы сплав ВТ8, аморфный бор, иодидный цирконий, химически чистые алюминий, молибден и кремний. При выплавке сплава, легированного цирконием, в шихту добавляли алюминий, молибден и кремний для сохранения их относительного количества таким же, как в ВТ8. Для того, чтобы имитировать условия охлаждения крупногабаритного слитка, все выплавленные сплавы подвергали отжигу в однофазной $\beta$-области при температуре $T=1050^{\circ} \mathrm{C}(\tau=30$ мин $)$ с последующим медленным охлаждением в печи. Полученные после отжига состояния сплавов обозначены в тексте как исходные литые состояния.

Перед проведением деформационно-термической обработки с помощью дифференциально-сканирующей калориметрии определяли температуру полиморфного превращения исследуемых сплавов. Она составила $T_{n n} \approx 1010^{\circ} \mathrm{C}$ для ВТ8 и ВТ8-0,1B, $T_{n n} \approx 905^{\circ} \mathrm{C}$ для BT8-20Zr-0,1B. Отметим, что снижение $T_{n n}$ соотносится с бинарной диаграммой Ti-Zr [1] и данными работы [6]. Отсутствие заметного влияния добавок бора на температуру полиморфного превращения в титановых сплавах отмечалось ранее [11].

Литые (после отжига при $T=1050^{\circ} \mathrm{C}$ ) заготовки сплава BT8-20Zr-0,1B подвергали всесторонней изотермической ковке и упрочняющей термической обработке. Условия обработки представлены в Таблице 2.

табл. 1. Составы исследуемых сплавов.

Table 1. The alloy compositions under study.

\begin{tabular}{|c|c|c|c|c|c|c|c|c|}
\hline \multirow{2}{*}{\multicolumn{2}{|c|}{$\begin{array}{l}\text { Обозначение сплава } \\
\text { Alloys designation }\end{array}$}} & \multicolumn{7}{|c|}{$\begin{array}{c}\text { Содержание элементов, вес. \% } \\
\text { Composition, wt. \% }\end{array}$} \\
\hline & & \multicolumn{2}{|c|}{$\mathrm{Ti}$} & \multirow{2}{*}{$\frac{\mathrm{Al}}{6,5}$} & \multirow{2}{*}{$\frac{\text { Mo }}{3,3}$} & \multirow{2}{*}{$\begin{array}{c}\mathrm{Si} \\
0,3\end{array}$} & \multirow{2}{*}{$\frac{B}{-}$} & \multirow{2}{*}{$\frac{\mathrm{Zr}}{-}$} \\
\hline BT8 & VT8 & $\mathrm{OCH}$. & bal. & & & & & \\
\hline BT8-0,1B & VT8-0.1 B & $\mathrm{OCH}$. & bal. & 6,5 & 3,3 & 0,3 & 0,1 & - \\
\hline BT8-20Zr-0,1B & VT8-20Zr-0.1B & осH. & bal. & 6,5 & 3,3 & 0,3 & 0,1 & 20 \\
\hline
\end{tabular}


Табл. 2. Условия обработки сплавов.

Table 2. Processing of the alloys.

\begin{tabular}{|c|c|}
\hline $\begin{array}{l}\text { Сплав (вес. \%) } \\
\text { Alloy (wt. \%) }\end{array}$ & $\begin{array}{l}\text { Условия обработки } \\
\text { The processing conditions }\end{array}$ \\
\hline $\begin{array}{l}\text { BT8, BT8-0,1B } \\
\text { VT8, VT8-0.1B }\end{array}$ & $\begin{array}{c}\text { литье + отжиг при } T=1050^{\circ} \mathrm{C} \text {, охлаждение с печью } \\
\text { cast }+ \text { anneal at } T=1050^{\circ} \mathrm{C} \text { and furnace cooling }\end{array}$ \\
\hline \multirow{4}{*}{$\begin{array}{l}\text { BT8-20Zr-0,1B } \\
\text { VT8-20Zr-0.1B }\end{array}$} & $\begin{array}{l}\text { 1) литье + отжиг при } T=1050^{\circ} \mathrm{C} \text {, охлаждение с печью; } \\
\text { 1) cast + anneal at } T=1050^{\circ} \mathrm{C} \text { and furnace cooling; }\end{array}$ \\
\hline & $\begin{array}{l}\text { 2) литье + отжиг при } T=1050^{\circ} \mathrm{C} \text {, охлаждение с печью + выдержка при } T=1000^{\circ} \mathrm{C} \text {, закалка в } \\
\text { воду }+ \text { старение при } T=700^{\circ} \mathrm{C} \text {; } \\
\text { 2) cast }+ \text { anneal at } T=1050^{\circ} \mathrm{C} \text { and furnace cooling }+ \text { solution treatment at } T=1000^{\circ} \mathrm{C} \text { and water } \\
\text { quenching + ageing at } T=700^{\circ} \mathrm{C} \text {; }\end{array}$ \\
\hline & $\begin{array}{l}\text { 3) литье + ВИК + закалка в воду с } T=1000^{\circ} \mathrm{C}+\text { старение при } T=700^{\circ} \mathrm{C} \text {; } \\
\text { 3) cast + MIF + solution treatment at } T=1000^{\circ} \mathrm{C} \text { and water quenching + ageing at } T=700^{\circ} \mathrm{C} \text {; }\end{array}$ \\
\hline & $\begin{array}{l}\text { 4) литье + ВИК + закалка в воду с } T=880^{\circ} \mathrm{C}+\text { старение при } T=600^{\circ} \mathrm{C} \\
\text { 4) cast }+ \text { MIF + solution treatment at } T=880^{\circ} \mathrm{C} \text { and water quenching + ageing at } T=600^{\circ} \mathrm{C}\end{array}$ \\
\hline
\end{tabular}

ВИК - всесторонняя изотермическая ковка

MIF - multiple isothermal forging

Деформационная обработка сплава BT8-20Zr-0,1B включала в себя всестороннюю изотермическую ковку при температуре $T=800^{\circ} \mathrm{C}$ на суммарную степень деформации $e \approx 2,7$ со скоростью деформации $\varepsilon=10^{-3}-10^{-2} \mathrm{c}^{-1}$. После этого полученное мелкозернистое состояние нагревали до $T=1000$ или $880^{\circ} \mathrm{C}$, выдерживали $\tau=30$ мин и закаливали в воду с последующим старением при $T=700$ и $600^{\circ} \mathrm{C}$ ( $\tau=2$ ч.), соответственно.

Из полученных после упрочняющей термической обработки состояний сплавов искровым способом вырезали плоские образцы на растяжение; размеры рабочей части образцов составляли $10 \times 3,5 \times 1,5 \mathrm{~mm}^{3}$. Образцы механически шлифовали и полировали перед испытаниями. Испытания на растяжение проводили при комнатной и повышенных температурах, для каждого состояния испытывали не менее 3 образцов.

Микроструктурные исследования были выполнены на сканирующем электронном микроскопе Mira-3 Tescan в режиме обратно-рассеянных электронов (BSE), обеспечивающем фазовый контраст. Из электронно-микроскопических снимков определяли средний размер колоний/зерен и толщину пластин. При изучении деформированной микроструктуры, полученной после горячей деформации, использовали также метод автоматического анализа картин дифракции обратно-рассеянных электронов (EBSDанализ) с шагом сканирования 0,2 мкм. Малоугловые границы с разориентировкой менее $2^{\circ}$, учитывая погрешность EBSD-анализа, были исключены из рассмотрения. Оценивая долю высокоугловых границ зерен, принимали во внимание границы с разориентировкой более $15^{\circ}$. Рентгеноструктурные измерения были выполнены на дифрактометре ДРОН-4 с использованием Со-К $а$ излучения.

\section{3. Результаты и обсуждение}

\section{1. Исходное состояние сплавов}

На рис. 1 представлены изображения микроструктуры сплавов в исходном литом состоянии. Видно, что модифицирование бором ведет к существенному измельчению размеров исходных $\beta$-зерен и $\alpha / \beta$ колоний, а легирование цирконием - к дополнительному измельчению размера колоний. Количественная оценка, выполненная для снимков с разным увеличением, подтвердила сделанную визуальную оценку (Таблица 3). Модифицирование бором приводит к уменьшению размера исходных $\beta$-зерен примерно на порядок и размера колоний примерно в шесть раз. Легирование цирконием обеспечивает дополнительное уменьшение размера колоний. В итоге, модифицирование бором и легирование цирконием обеспечивают уменьшение размера исходных $\beta$-зерен и размера колоний примерно на порядок. Толщина $\alpha$ пластин от состава сплава меняется незначительно (Таблица 3).

\section{2. Влияние закалки и старения на фазовый состав}

На рис. 2 представлены дифрактограммы, полученные для сплава BT8-20Zr-0,1B после закалки из $\beta$ фазовой области и последующего старения. Закалка ведет к развитию мартенситного превращения $\beta \rightarrow \alpha$ ", что не происходит в случае ВТ8 [1]. Как известно [1], $\alpha$ "-фаза имеет орторомбическую решетку, дающую характерное расщепление некоторых интерференционных линий. Кроме того, после закалки в сплаве сохраняется остаточная 


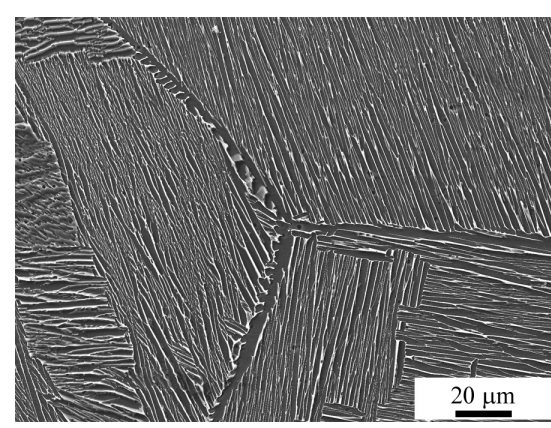

a

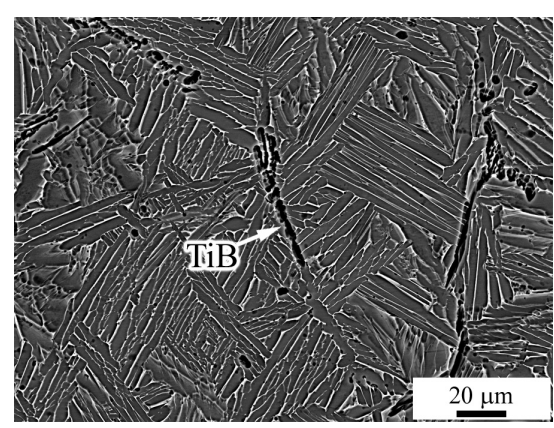

b

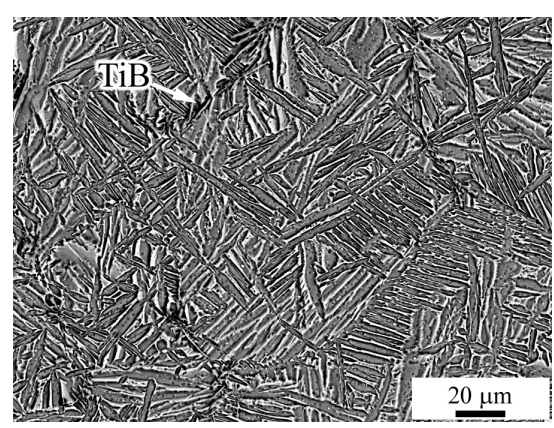

C

Рис. 1. Исходное состояние сплавов: (a) BT8, (b) BT8-0,1B, (c) BT8-20Zr-0,1B (снимки получены в режиме BSE).

Fig. 1. BSE images of the alloys in as-cast conditions: (a) VT8, (b) VT8-0.1B, (c) VT8-20Zr-0.1B.

Табл. 3. Количественные параметры микроструктуры сплавов в исходном литом состоянии $\left(D_{\beta}-\right.$ размер исходных $\beta$-зерен, $d$ - размер колоний, $b_{\alpha}-$ толщина $\alpha$-пластин).

Table 3. Quantitative microstructural parameters of the alloys in the initial as-cast conditions $\left(D_{\beta}-\right.$ the size of prior $\beta$-grains, $d-$ the colony size, $b_{\alpha}$ - the thickness of $\alpha$-lamellae).

\begin{tabular}{|c|c|c|c|}
\hline \multirow{2}{*}{$\begin{array}{c}\text { Сплав } \\
\text { Alloy }\end{array}$} & \multicolumn{3}{|c|}{$\begin{array}{c}\text { Микроструктурные параметры } \\
\text { Microstructural parameters }\end{array}$} \\
\cline { 2 - 4 } & $\begin{array}{c}D_{\beta}, \text { мкм } \\
D_{\beta}, \mu \mathrm{m}\end{array}$ & $\begin{array}{c}d, \text { мкм } \\
d, \mu \mathrm{m}\end{array}$ & $\begin{array}{c}b_{\alpha}, \text { мкм } \\
b_{\alpha}, \mu \mathrm{m}\end{array}$ \\
\hline BT8 & $2000 \pm 400$ & $250 \pm 25$ & $1,9 \pm 0,4$ \\
VT8 & $200 \pm 40$ & $40 \pm 5$ & $2,2 \pm 0,4$ \\
\hline $\begin{array}{c}\text { BT8-0,1B } \\
\text { VT8-0.1B }\end{array}$ & $190 \pm 40$ & $25 \pm 5$ & $2,5 \pm 0,4$ \\
\hline $\begin{array}{c}\text { BT8-20Zr-0,1B } \\
\text { VT8-20Zr-0.1B }\end{array}$ & & & \\
\hline
\end{tabular}

$\beta$-фаза (рис. 2a). Следует отметить, что образование орторомбической $\alpha$ "-фазы вместо обычной при закалке таких сплавов как ВТ6, ВТ8 $\alpha^{\prime}$-фазы, по всей видимости, связано с повышенным содержанием циркония [12]. Образование $\alpha$ "-фазы после закалки в воду также наблюдали при высоком легировании цирконием сплава Ti-6.5Al-4V [7]. Последующее старение приводит к развитию превращений $\alpha^{\prime \prime} \rightarrow \alpha+\beta$ и $\beta \rightarrow \alpha+\beta$, т. е. структура становится обычной двухфазной.

\section{3. Влияние деформационной и термической обработки на микроструктуру}

На рис. 3 представлена микроструктура сплава BT8-20Zr-0,1B, полученная после всесторонней изотермической ковки, а также после ковки и упрочняющей термической обработки. Видно, что горячая деформация приводит к формированию однородной мелкозернистой структуры: средний размер зерен составил $d=2 \pm 0,15$ мкм, доля высокоугловых границ зерен, согласно данным EBSD-анализа - 78\%. Благодаря по-

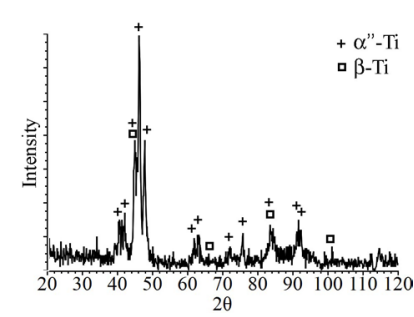

a

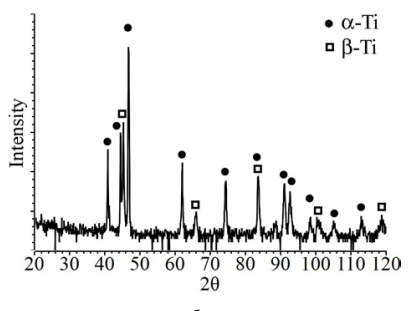

$\mathrm{b}$
Pис. 2. Дифрактограммы, полученные для литого сплава BT8-20Zr-0,1B: a - после закалки в воду от температур $\beta$ фазовой области, $\mathrm{b}-$ после закалки от температур $\beta$ фазовой области и старения.

Fig. 2. X-Ray curves obtained for the cast VT8-20Zr-0.1B alloy: $\mathrm{a}-$ after solution treatment in the $\beta$ phase field followed by water quenching, $\mathrm{b}-$ after solution treatment in the $\beta$ phase field followed by water quenching and ageing.

ниженной температуре полиморфного превращения и измельченной литой структуре сплав имеет высокую деформируемость и относительно низкие напряжения течения при $T=800^{\circ} \mathrm{C}$, а мелкозернистую микроструктуру практически во всем объеме заготовки удается получить с использованием сравнительно небольшой деформации, что выгодно отличает сплав от обычного сплава ВТ8, в котором для получения однородной мелкозернистой структуры, как правило, требуется бо́льшая накопленная степень деформации [11].

После закалки от $\beta$ фазовой области и старения при $T=700^{\circ} \mathrm{C}$ в сплаве BT8-20Zr-0,1B формируется тонкодисперсная пластинчатая $\alpha+\beta$ структура (Рис. $3 \mathrm{~b}$ ). В случае закалки от верхней части $\alpha+\beta$ фазовой области и старения при $T=600^{\circ} \mathrm{C}$ формируется дуплексная структура со средним размером зерен первичной $\alpha$-фазы около 2 мкм и тонкодисперсной пластинчатой составляющей. Средняя толщина пластин, оцененная по снимкам с бо́льшим увеличением (не приведенным здесь), составила около 150 нм в случае старения при $T=700^{\circ} \mathrm{C}$ и около 100 нм в случае старения при $T=600^{\circ} \mathrm{C}$. Таким образом, упрочняющая термическая обработка позволяет получить в сплаве очень тонкодисперсную структуру с нанометрической толщиной пластин. По всей видимости, этому способствует тот факт, что при закалке мелкозернистого сплава от температур $\beta$ или $\alpha+\beta$ фазовой области имеет место необычное для таких двухфазных 


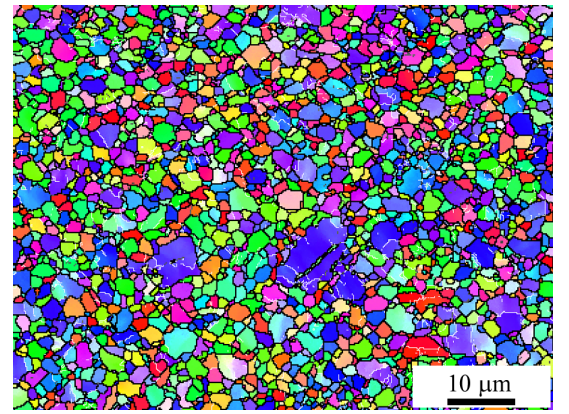

a

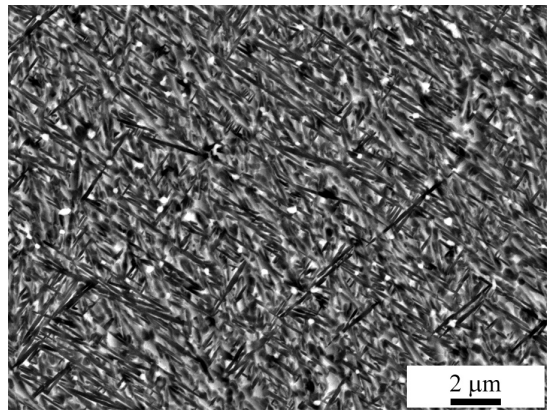

$\mathrm{b}$

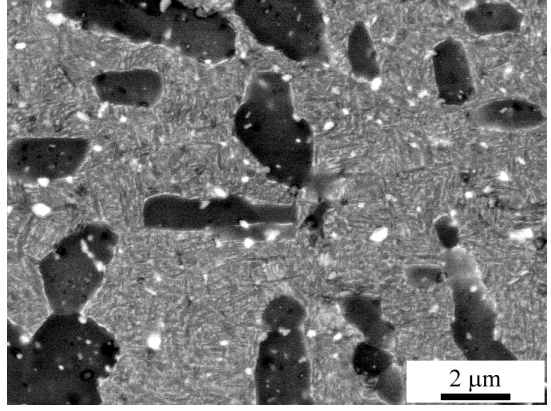

C

Рис. 3. Микроструктура сплава BT8-20Zr-0,1B: (a) - после всесторонней изотермической ковки (EBSD-карта), (b) - после ковки, закалки от $T=1000^{\circ} \mathrm{C}$ и старения при $T=700^{\circ} \mathrm{C}$, (c) - после ковки, закалки от $T=880^{\circ} \mathrm{C}$ и старения при $T=600^{\circ} \mathrm{C}$.

Fig. 3. SEM images of the VT8-20Zr-0.1B alloy: (a) - after multiple isothermal forging (EBSD map), (b) - after forging, solution treatment at $T=1000^{\circ} \mathrm{C}$ followed by water quenching and ageing at $T=700^{\circ} \mathrm{C},(\mathrm{c})-$ after forging, solution treatment at $T=880^{\circ} \mathrm{C}$ followed by water quenching and ageing at $T=600^{\circ} \mathrm{C}$.

титановых сплавов мартенситное превращение $\beta \rightarrow \alpha^{\prime \prime}$ с образованием орторомбической $\alpha^{\prime \prime}$-фазы, обычно наблюдаемое при закалке титановых сплавов с более высоким коэффициентом $\beta$-стабилизации.

\section{4. Механические свойства при растяжении}

На рис. 4 представлены механические свойства при растяжении, полученные для сплава BT8-20Zr-0,1B после всесторонней изотермической ковки и упрочняющей термической обработки. Для сравнения также представлены взятые из справочника [2] свойства сплава ВТ8 после деформационной обработки, закалки от верхней части $\alpha+\beta$ фазовой области $\left(T=920-940^{\circ} \mathrm{C}\right)$ и старения при $T=550^{\circ} \mathrm{C}$. Сплав BT8-20Zr-0,1B после закалки от верхней части $\alpha+\beta$ области и старения при $T=600^{\circ} \mathrm{C}$ показал $\sigma_{\text {в }}=1560$ МПа при $20^{\circ} \mathrm{C}$ и $\sigma_{\mathrm{B}}=1230 \mathrm{MПа} \mathrm{при} 500^{\circ} \mathrm{C}$ при сохранении приемлемой пластичности ( $\delta=4 \%$ при комнатной температуре), сравнимой в диапазоне $20-500^{\circ} \mathrm{C}$ с полученной для ВТ8.
При $T=600^{\circ} \mathrm{C}$ пластичность сплава BT8-20Zr-0,1B в обоих состояниях оказалась выше, чем в случае ВТ8 (Рис. 4b). По сравнению со сплавом ВТ8 прирост прочности при $20-500^{\circ} \mathrm{C}$, т. е. в диапазоне рабочих температур сплава, составил $30-40 \%$. При этом, как и ожидалось, сплав с дуплексной структурой показал несколько бо́льшую прочность и пластичность, чем с тонкодисперсной пластинчатой структурой.

Сопоставляя механические свойства с микроструктурными наблюдениями и принимая во внимание известные данные о влиянии циркония, можно заключить, что существенное влияние на упрочнение экспериментального сплава ВT8-20Zr-0,1B имело несколько факторов: 1) твердорастворное упрочнение благодаря цирконию, 2) необычное для ВТ8 мартенситное превращение с образованием орторомбической $\alpha^{\prime \prime}$-фазы, которое наблюдается для $\beta$ и $\alpha+\beta$ титановых сплавов с более высоким коэффициентом $\beta$-стабилизации, 3 ) формирование в результате старения тонкодисперсной пластинчатой структуры с нанометрической толщиной пластин,
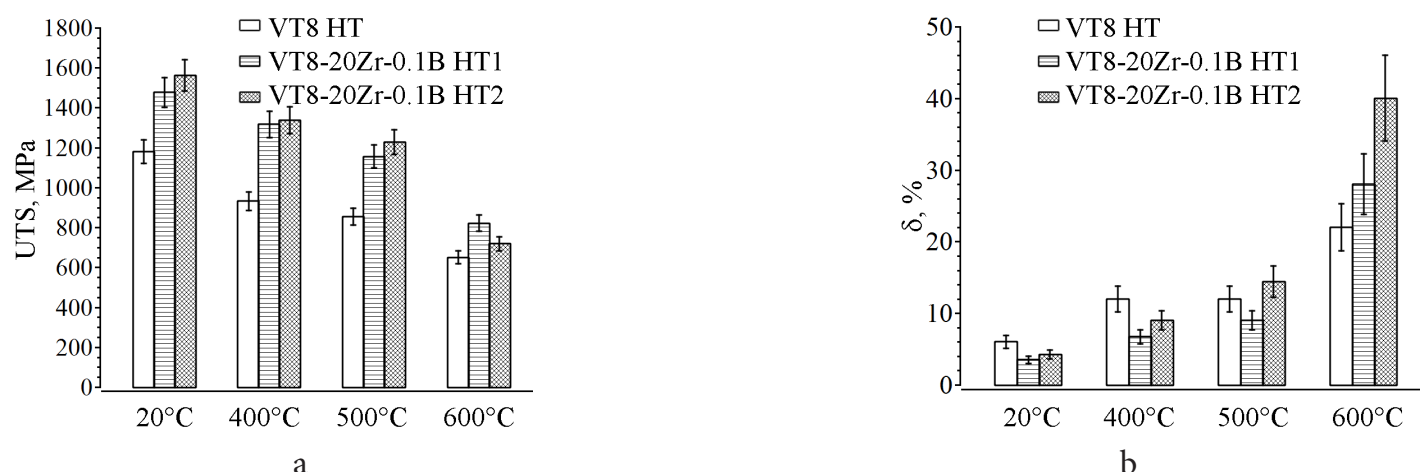

Pис. 4. Механические свойства при растяжении сплавов ВТ8-20Zr-0,1B и ВТ8, полученные после схожей деформационнотермической обработки, включавшей в себя горячую деформацию и последующую упрочняющую термическую обработку: $\mathrm{HT}$ - термическая обработка, состоящая из закалки от $T=920-940^{\circ} \mathrm{C}$ и последующего старения при $T=550^{\circ} \mathrm{C} ; \mathrm{HT} 1-$ термическая обработка, состоящая из закалки от $T=1000^{\circ} \mathrm{C}$ и последующего старения при $T=700^{\circ} \mathrm{C}$; $\mathrm{HT} 2-$ термическая обработка, состоящая из закалки от $T=880^{\circ} \mathrm{C}$ и последующего старения при $T=600^{\circ} \mathrm{C}$.

Fig. 4. Tensile properties of the VT8-20Zr-0.1B and VT8 alloys obtained after similar hot forging and strengthening heat treatment: $\mathrm{HT}$ - heat treatment consisted of solution treatment at $T=920-940^{\circ} \mathrm{C}$ followed by water quenching and ageing at $T=550^{\circ} \mathrm{C} ; \mathrm{HT} 1-$ heat treatment consisted of solution treatment at $T=1000^{\circ} \mathrm{C}$ followed by water quenching and ageing at $T=700^{\circ} \mathrm{C}$; HT2 - heat treatment consisted of solution treatment at $T=880^{\circ} \mathrm{C}$ followed by water quenching and ageing at $T=600^{\circ} \mathrm{C}$. 
4) сдерживание роста $\beta$-зерен при нагреве под закалку благодаря присутствию боридов, что способствовало достижению более тонкодисперсной структуры.

По классификации А.И. Хорева [4], полученные для сплава BT8-20Zr-0,1B свойства дают основания причислить этот сплав к сверхпрочным титановым сплавам (с прочностью 1300 - 1800 МПа и более), что раньше достигалось только для $\beta$ и $\alpha+\beta$ титановых сплавов с более высоким содержанием $\beta$-стабилизирующих элементов и относительно низкой рабочей температурой. Как отмечалось, цирконий относится к нейтральным упрочнителям, который предположительно не понизит жаропрочные свойства (сопротивление ползучести) сплава, а наоборот - повысит их [13]. Можно ожидать и повышения усталостной прочности в результате легирования цирконием.

Рассматривая удельную прочность нового сплава при $T=20$ и $500^{\circ} \mathrm{C}$ в сравнении с другими титановыми сплавами, можно сделать заключение, что несмотря на повышение плотности сплава из-за легирования цирконием до $\rho \approx 4,95 \mathrm{r} / \mathrm{cm}^{3}$, удельная прочность сплава при комнатной температуре уступает только самым высокопрочным титановым сплавам, а при $T=500^{\circ} \mathrm{C}$ значение удельной прочности, которое составило $\sigma_{\mathrm{B}} / \rho \approx 248$ Па $/ \mathrm{\Gamma} \times \mathrm{cm}^{-3}$, является рекордным при этой температуре для известных титановых сплавов. Отметим, что максимальная удельная прочность титановых сплавов при $T=500^{\circ} \mathrm{C}$, согласно $[2,3]$, не превышает $160-180 \mathrm{MПа} / \mathrm{r} \mathrm{Cm}^{-3}$. Например, наиболее прочные $\alpha+\beta$ и псевдо $\alpha$ титановые сплавы с рабочей температурой до $500-600^{\circ} \mathrm{C}$, такие как ВТ9, ВТ25, ВТ25У, ВТ38, BT18У, ВТ41, имеют прочность при $T=500^{\circ} \mathrm{C}$ не превышающую $\sigma_{\mathrm{B}}=800-900 \mathrm{MПа} \mathrm{[1-3].}$

Таким образом, высокое легирование цирконием вместе с модифицированием бором вполне можно использовать при разработке новых конструкционных титановых сплавов с уникальными комбинациями свойств. Дальнейшие исследования должны уточнить механизмы упрочнения экспериментального сплава и влияние циркония на его жаропрочные и усталостные свойства.

\section{4. Заключение}

1. Модифицирование бором обеспечивает измельчение размера исходных $\beta$-зерен и $\alpha / \beta$ колоний в слитке примерно на порядок, а легирование цирконием дополнительно измельчает размер колоний в слитке.

2. Легирование сплава ВТ8 цирконием в количестве 20 вес.\% снижает температуру полиморфного превращения примерно на $100^{\circ} \mathrm{C}$. Наряду с измельчением структуры слитка, это способствует повышению деформируемости (обрабатываемости) сплава при повышенных температурах и облегчает формирование мелкозернистой структуры с преимущественно высокоугловыми границами зерен.

3. Легирование сплава ВТ8 20 вес.\% циркония значительно повышает эффективность термического упрочнения. Прочность сплава ВТ8-20Zr-0,1B при $20-500^{\circ} \mathrm{C}$ после всесторонней изотермической ковки и упрочняющей термической обработки оказалась на $30-40 \%$ выше прочности ВТ8 после схожей деформационно-термической обработки при близких значениях пластичности. Для сплава ВТ8-20Zr-0,1B было получено: $\sigma_{\mathrm{B}}=1560 \mathrm{MПа}$ и $\delta=4 \%$ при комнатной температуре, $\sigma_{\mathrm{B}}=1230$ МПа и $\delta=14 \%$ при $T=500^{\circ} \mathrm{C}$.

4. Закалка сплава BT8-20Zr-0,1B в воду от температур $\beta$ фазовой области приводит к необычному для титанового сплава с относительно невысоким коэффициентом $\beta$-стабилизации мартенситному превращению $\beta \rightarrow \alpha$ " с сохранением остаточной $\beta$-фазы, а последующее старение - к образованию тонкодисперсной пластинчатой структуры с нанометрической толщиной пластин, обеспечивающей значительное упрочнение.

5. Экспериментальный сплав BT8-20Zr-0,1B можно отнести к сверхпрочным титановым сплавам. Достигнутая удельная прочность при $T=500^{\circ} \mathrm{C}$ $\left(\sigma_{\mathrm{B}} / \rho \approx 248 \mathrm{MПа} / \mathrm{r} \times \mathrm{cm}^{-3}\right)$ является рекордной при этой температуре для известных титановых сплавов.

Благодарность/Aknowledgements. Работа выполнялась в рамках программы фундаментальных исследований Российской академии наук, регистрационный номер - 01201455192.

\section{Литература/References}

1. Metallography of Titanium Alloys. Ed. by N. F. Anoshkin. Moscow. Metallurgy (1980) 464 p. (in Russian) [Металлография титановых сплавов. Под ред. Н. Ф. Аношкина М. «Металлургия», (1980) 464 с.].

2. A. A. Il'in, B. A. Kolachev, I.S. Pol'kin. Titanium alloys. M. VILS-MATI. (2009) 519 p. (in Russian) [А. А. Ильин, Б.А. Колачев, И.С. Полькин. Титановые сплавы. М. ВИЛС-МАТИ. (2009) 519 с.].

3. C. Leyens, M. Peters, «Titanium and Titanium Alloys, Fundamentals and Applications». Weinheim, Germany (2003) $513 \mathrm{p}$.

4. A.I. Khorev. Technology of mechanical engineering. 6, 5-8 (2012) (in Russian) [А.И. Хорев. Технология машиностроения. 6, 5-8 (2012)].

5. R. Jing, S.X. Liang, C.Y. Liu, M.Z. Ma, X.Y. Zhang, R. P. Liu. Mater. Sci. Eng. A. 552, 295-300 (2012).

6. R. Jing, S.X. Liang, C. Y. Liu, M.Z. Ma, R. P. Liu. Mater. Sci. Eng. A. 559, 474- 479 (2013).

7. J. Zhu, A. Kamiya, T. Yamada, W. Shi, K. Naganuma. Mater. Sci. Eng. A. 339, 53-62 (2003).

8. R. Srinivasan, D. Miracle, S. Tamirisakandala. Mater. Sci. Eng. A. 487, $541-551$ (2008).

9. S. Roy, A. Sarkar, S. Suwas. Mater Sci Eng: A. 528, 449 - 458 (2010).

10. R. A. Gaisin, V.M. Imayev, R.M. Imayev, E. R. Gaisina. Letters on Materials. 5 (2), $124-128$ (2015). (in Russian) [Р. А. Гайсин, В. М. Имаев, Р. М. Имаев, Э. Р. Гайсина. Письма о материалах. 5 (2), $124-128$ (2015)].

11. V.M. Imayev, R.A. Gaisin, R.M. Imayev. Mater. Sci. Eng. A. 641, $71-83$ (2015).

12. C. Lin, G. Yin, Y. Zhao, P. Ge, Z. Liu. Mater. Chem. Phys. 125, $411-417$ (2011).

13. J. Soyama, M. Oehring,W. Limberg, T. Ebel, K. U. Kainer, F. Pyczak. Mater. Design. 84, 87 - 94 (2015). 